\title{
Paydaş Analizi
}

DOI: 10.26466/opus.574116

*

\author{
M.Zeki İlgar*- Semra Coşgun İlgar ** \\ * Dr.Öğretim Üyesi, Biruni Üniversitesi, Eğitim Fakültesi, İstanbul/Türkiye \\ E-Posta: zilgar@biruni.edu.tr \\ ORCID: $0000-0002-5516-0752$ \\ ** Uzman Psikolojik Danışman. \\ E-Posta: semracosgunilgar2018@gmail.com \\ ORCID: $\underline{0000-0003-1439-1666}$
}

\section{Öz}

Bir nitel araştırma ve istatistik yöntemi olarak; bir soruna çözüm üretirken veya bir proje hazırlarken mevcut sorundan veya olası projeden etkilenebilecek tüm paydaş grupların, sorun/proje ile ilişkilerinin, güçlerinin ve etkilerinin, katılım stratejilerinin, belirlenmesinde ve proje sonuçlarının değerlendirilmesinde kullanılmaktadır. Başka bir anlatımla paydaş analizi araştırmaya konu olan mevcut sorundan veya olası projeden etkilenebilecek; tüm paydaş gruplarını; bu grupların sorun/proje ile ilişkilerinin; güçlerinin ve etkilerinin; katılım stratejilerinin belirlenmesi yöntemidir.Bu çalışma, stratejik planlama yapanlara, yatırım ve iş analistlerine, araştırma alanında çalışanlara ve proje hazırlayanlara paydaş analizi tekniğini kullanma konusunda yeterlik kazandırmayı amaçlamaktadır. Ülkemizde son yıllarda artan, araştırma ve uygulama projesi hazırlama,stratejik plan hazırlama, iş analizi yapma kapsamında çalışanların ciddi hatalar yaptıkları, kopyalamayı tercih ettikleri veya yüzeysel davrandıkları görülmektedir. Bu çalışmayla araştırmacılara rehberlik etmek amaçlanmıştır. Çalışmayı önemli kılan; özellikle bilimsel araştırma veya uygulama projesi hazırlayanların, stratejik plan hazırlayanların ve iş analizi yapanların sürecin başındayken paydaş analizi yapmalarının başarı şanslarını artıracağı gerçeğidir. Derleme mahiyetinde hazırlanan bu çalışma üç bölümden oluşmaktadır. Birinci bölümde konuya giriş yapılmış; ikinci bölümde paydaş analizinin tanıtımı ve tanımları ele alınmış; üçüncü bölümde paydaş analizinin aşamaları ortaya konulmuştur.

Anahtar Kelimeler: paydaş, paydaş analizi. 


\title{
Stakeholder Analysis
}

\begin{abstract}
As a qualitative research and statistical method, stakeholder analysis is used while producing solution to a problem or preparing a project; the method is used for determining problem/project relations, analyzing power and effect, researching accession strategies of all of the stake-holders that may be affected from the possible project and for evaluat-ing project results. In other words, stakeholder analysis is a method of determining re-lations of stakeholders with the problem/project, their power in the process or impact on it, and their strategies of accession; the stake-holders in question are affected either from the subject of a research or from a possible project This study aspires to provide competence to strategic planners, investment and business analysts, professionals in the field of research and project developers in using the stakeholder analysis technique. In our country, it has been widely seen that researchers or professionals make serious mistakes, prefer to copy, or behave superficially within the scope of developing research and implementation project, preparing a strategic plan and conducting business analysis. It has been aimed to guide the researchers with this study. This study is invaluable in the sense that stakeholder analysis at the very beginning of the process will increase the chances of success for the ones preparing scientific research or implementation projects, strategic planners and business analysts. This study prepared as a compilation is comprised of three parts: The first part includes the introduction. In the second part, the definitions and promotions of stakeholder analysis are discussed and in the third section, the stages of stakeholder analysis are put forward.
\end{abstract}

Keywords: Stakeholder, stakeholder analysis. 


\section{Giriş}

Paydaş analizi yöntem olarak; stratejik plan, araştırma ve uygulama projesi hazırlarken, bir soruna çözüm üretirken; sunulan hizmetten; mevcut sorundan veya olası projeden etkilenebilecek tüm paydaş grupların, hizmet/sorun/proje ile ilişkilerinin, güçlerinin ve etkilerinin, katılım stratejilerinin belirlenmesinde ve proje sonuçlarının değerlendirilmesinde kullanılmaktadır. Başka bir anlatımla paydaş analizi; stratejik plan hazırlarken, kurumun güçlenmesine katkı sunabilecek paydaşları araştırırken; iş analizi yaparken; proje hazırlarkenmevcut sorundan veya olası projeden etkilenebilecek, tüm paydaş gruplarının, bu grupların sorun/proje ile ilişkilerinin, güçlerinin ve etkilerinin, katılım stratejilerinin belirlenmesinde kullanılan bir analiz yöntemidir.

Toplam kalite yönelimli yeni yönetim anlayışının gereği olarak stratejik plan hazırlayan kurum görevlilerinin bu yöntemin mantığını anlamaları ve yöntemi bilerek uygulamaları önemli görünmektedir. Günümüzde giderek yaygınlaşan hizmet ve iş analizlerinde, stratejik planlarda, araştırma ve uygulama projelerinde paydaşların iyi analiz edilmesi önem kazanmaktadır. Özellikle proje yöneticilerinin doğru paydaşlar edinmesi projenin gerçekleşmesi açısından önemli görünmektedir.

\section{Paydaş ve Paydaş Analizi}

Paydaş kavramı günümüzde kullanılan anlamıyla ilk kez Freeman(1984) tarafından "bir kurumun amaç ve hedeflerinin başarıyla gerçekleştirilmesini etkileyen ya da bu başarıdan etkilenen birey ya da gruplar" olarak tanımlanmıştır. İlgili paydaşların kimler olduğu belirlenerek bu paydaşlara ilişkin verilerin toplanması ve toplanan bu verilerin analiz edilerek kurum için önemli bilgilere dönüştürülmesinin daha sonraki dönemlerde alınacak olan kararlara olumlu yönde katkıda bulunması beklenmektedir (akt. Sönmez ve Uğurluoğlu, 2017, s.224).

Paydaş, bir işletmede çalışan, işletmenin organizasyon yapısında yer alan iç ve diş aktörler olarak tanımlanmaktadır. Herhangi bir sektördeki proje sürecinde yer alan projeden olumlu veya olumsuz etkilenen ve proje sürecine etki edebilecek tüm aktörler de paydaşlarolarak adlandırılmak- 
tadır. Bir sektör paydaşları ise; sektörde rol alan, faaliyet gösteren, sektörden etkilenebilen veya sektörü etkileyebilen aktörler, gruplar, kurumlar veya organizasyonlardır (Uygun, 2018, s.97).

Paydaş kavramına ve yarattığ1 etkilere olan ilgi daha ziyade paydaş yaklaşımıyla başlamıştır. Paydaş yaklaşımı, işletmelerin faaliyet alanlarına, yapısına ve bulunduğu yöreye göre farklı paydaş ağının etkisi altında olduğunu ve işletmelerin ayakta kalmalarının ve başarılı olmalarının bu paydaşların beklenti ve ihtiyaçlarını karşılamaktan geçtiğini savunmaktadır (Sarıkaya, 2011, s.43). Paydaşlar organizasyonun faaliyetlerinden olumlu ya da olumsuz, doğrudan ya da dolaylı etkilenecek kişi ve kurumlardır (Ekin, 2016).

Paydaş Analizi; paydaşın, kuruluşun faaliyet ve hizmetlerini yönlendirme, destekleme veya olumsuz etkileme gücü, kuruluşun ise, paydaşın beklenti ve taleplerinin karşılanması konusuna verdiği öncelik gibi başlıklar ile paydaşların kim oldukları, ne düşündükleri, ne düzeyde etkiye sahip oldukları, kendileriyle nasıl ilişki kurulacağı, nasıl bilgilendirilecekleri, kurulan iletişimin sürekliliği, ilişkilenme süresince oluşabilecek beklenmedik durumlara yönelik stratejilerin belirlenmesi gibi sorulara doğru cevaplar sunan pazar araştırmaları sürecidir (arveda.com).

Reed'e göre (2008), paydaş analiz sürecini; paydaşların belirlemesi, paydaşların sınıflandırılması ve paydaşlar arasındaki ilişkiler olarak üç ana bölümde incelemiştir. Paydaş analiz sürecinde paydaşlar arası ilişkilerin tespitinin yapılması, sektördeki eksikliklerin ve aksamaların keşfedilmesi açısından çok önem taşımaktadır.

Paydaş analizi süreci, kurum ile ilişki düzeylerini belirlemek üzere aktörlerin bilgilerinin toplanması ile başlamaktadır. Paydaşların sürecin planlaması ve uygulanmasındaki katkıları paydaş analiz ile çeşitli yöntemler geliştirilip uygulanarak yapılmaktadır (Varvasovszky \& Brugha, 2000; akt. Uygun, 2018). Bu bağlamda, paydaş analizi örgüt içi veya örgütler arası paydaşların sektördeki durumlarını, çıkarlarını ve ilişkilerini ortaya koymaktır. Bu süreç, sistematik bilgi toplama ve analiz etmek ile tamamlanmaktadır. Belirli bir konu üzerinde paydaşların görüşleri alınarak analizler yapılabileceği gibi, daha kapsamlı olarak sektörel paydaş ilişki analizi de yapılabilmektedir(Uygun, 2018, s. 99). 


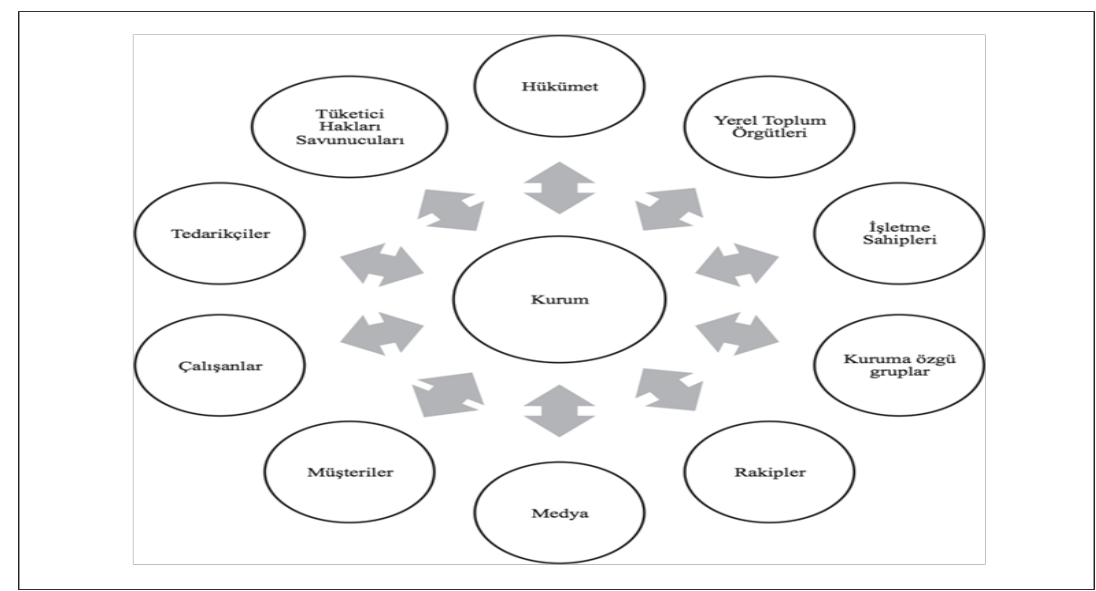

Şekil 1. Bir Kurumun Olası Paydaşları

Kaynak: Freeman, R. E. (1984). Strategic Management: A stakeholder approach. Pitman, Boston(akt. Sönmez ve Uğurluoğlu, 2017, s.225).

Yukarıdaki şekilde stratejik yönetim için bir kurumun olası paydaşlarının gösterimi yer almaktadır. Kurumun ölçeğine, yapısına, bulunduğu sektöre ve değerlendirmek istediği stratejisine göre paydaşlarının listesi ve alt grupları değişiklik gösterebilmektedir. Şekilde de görüldüğü gibi paydaşlar kurumu hem etkilemekte hem de kurumun faaliyetlerinden etkilenmektedir.

Gupta (1995) paydaş analizini, paydaşların ilgi, baskınlık ve özgüllük düzeyini belirlemek, hem paydaşlar arasında hem de paydaşlar ile kurum arasındaki güç ilişkilerini tanımlamak ve ilgili politik faaliyetlerin eylem planlarını ve gerçekleştirileceği zamanı belirlemek için yapılan bir analiz olarak tanımlamaktadır(akt.Sönmez ve Uğurluoğlu, 2017, s.225).

Varvasovszky ve Brugha (2000) paydaş analizini, bireysel ya da örgütsel aktörler ile ilgili bilgilerin toplanması ve böylece davranış, niyet ve kurum ile ilişki düzeylerini anlamak ve sürecin planlanması ve uygulanmasındaki katkılarını ve etkilerini ortaya koymak için geliştirilmiş araç ya da araçlar bütünü olan bir yaklaşım olarak ifade etmektedirler. Mushove ve Vogel (2005) paydaş analizini ilgili politikadaki görevlerine, kurum ile ilişki düzeylerine ve sistem, konu ya da kaynaklar ile ilgili göreceli ilgi düzeylerine göre anahtar aktörleri ya da paydaşları tanımlayarak bir sistemi anlamak için geliştirilmiş bir yaklaşım ya da araçlar bütünü olarak 
belirtmektedirler. Schmeer (1999a) paydaş analizini, bir politika geliştirilirken ve/veya uygulanırken hangi tarafların dikkate alınacağını belirlemek için kalitatif bilgilerin sistematik bir şekilde toplanmasını ve analiz edilmesini içeren bir süreç olarak ifade etmektedir(akt. Sönmez ve Uğurluoğlu, 2017, s.226).

Jepsen ve Eskerod (2009) paydaş analizini, önemli paydaşların tanımlanmasına, paydaşların katkılarının belirlenmesine ve bu katkılarına göre önceliklendirmesine ve her bir paydaşı etkilediği düşünülen stratejiler hakkında bir karar verilmesine olanak sağlayan faaliyetler bütünü olarak ifade etmektedirler. Reed (2008) ise paydaş analizini herhangi bir karar ya da faaliyetten etkilenen sosyal ya da doğal sistemlerin belirlenmesi, sistemin bütününü ya da parçalarını etkileyen ya da etkilenen birey ya da grupların tanımlanması, karar verme aşamasına katkıda bulunan bu birey ya da grupların önceliklendirilmesi faaliyetlerinden oluşan bir süreç olarak tanımlamaktadır (akt. Sönmez ve Uğurluoğlu, 2017, s.226).

Literatürde de görüldüğü gibi paydaş analizi ile ilgili birbirinden farklı birçok tanım bulunmaktadır. Bu tanımların her birinin içerdiği noktalara bakıldığında bir politikadan etkilenen ya da etkileyen grupların tanımlanması, tanımlanan bu grupların katkılarına göre sinıflandırılması ve elde edilen tüm bu bilgilerin ilgili politikayı daha iyi hale nasıl getirebileceği konusunda kullanılması gerekliliği vurgulanmıştır (Sönmez ve Uğurluoğlu, 2017, s. 226).

\section{Paydaş Analizinin Önemi}

Paydaş Analizi, araştırma ve uygulama projesi hazırlamaya başlarken özenle yapıldığında projenin etkili ve verimli olmasını sağlama açısından önemlidir. Ülkemizde UNESCO, AB, TÜBİTAK, kalkınma ajansları, çeşitli bakanlıklar, sivil toplum kuruluşları ve yerel yönetimler tarafından desteklenen; farklı ölçeklerde bütçeye sahip, reklamı çok iyi yapılan projelerden hedeflenen sonuçlar alınamadığı bilinen bir gerçektir.

Paydaş Analizi, stratejik planlamanın temel unsurlarından biridir. Organizasyonun etkileşim içinde olduğu kişi ve kurumların analiz edilmesini ve bu ilişkilerin de stratejik plan doğrultusunda yönetilmesini esas alır. Paydaş analizi ile paydaşlarla etkili bir iletişim kurularak paydaşların 
görüş ve beklentilerinin tespit edilmesi, organizasyonun faaliyetlerinin etkin bir şekilde gerçekleştirilmesine engel oluşturabilecek unsurların saptanması ve bunların giderilmesi için stratejiler oluşturulması sağlanır; ayrıca paydaşların görüş, öneri ve beklentilerinin stratejik planlama sürecine dahil edilmesiyle planın bu kesimlerce sahiplenilmesi ve planın uygulanma şansının artması amaçlanır (Ekin, 2016).

Yatırım yaparken veya iş analizi sürecinde paydaşların iyi analiz edilmediği durumlarda önemli zararlar oluşmakta, kaynaklar israf edilmektedir. Genç girişimcilere verilen eğitimin bir boyutunu paydaş analizi yapma becerisinin kazandırılması olarak planlanmalıdır. Yatırımcıların paydaş analizi yapmaları veya yaptırmaları başarılı olma olasılıklarını artıracaktır.

Özetle ifade etmek gerekirse paydaş analizi süreci, proje yöneticilerinin ve yürütücülerinin hazırladıkları projelerin geniş etki yaratmasında ve başarıya ulaşmasında önemli görünmektedir. Bu çalışmayı yaparken özellikle akademisyenlerin yararlanması hedeflenmiştir.

\section{Paydaş Analizi'nin Kullanıldığı Alanlar}

Paydaş analizi daha çok proje hazırlarken, projenin başarıya ulaşması ve etkisinin artırılması için paydaşların tesbiti, araştırılması ve iletişimin kurulmasıyla gerçekleşen analiz işlemi sonucu belirlemede etkili görünmektedir. Proje hazırlama konusunda verilen eğitimlerde paydaş analizi konusunun ayrıntılı olarak anlatılması, konuya dair bilgilendirme yapılması projenin başarısını artıracaktır.

Stratejik yönetim anlayışı gereği hazırlanan stratejik planlarda paydaşların tesbit edilmesi ve analiz edilmesinde bu tekniğin bilinçli olarak kullanılması, işletmelerin ve kamu kurumlarının verimlilik artışında ve kalite konusunda etkili olacaktır. Yöneticiler bu analizlerden yararlanarak yapacakları planlamalarda daha isabetli sonuçlara ulaşabilecektir.

İş Analizi yaparken gereksinim analizi sürecinden önce, iş analistinin proje yönetimi yaklaşımı ile üzerinde çalışılacak talebin kapsamının çizildiği, işe daha tepeden bakarak büyük resmi görmesi gerektiği bir süreç vardır. Tam burada; gereksinim analizine başlamadan önce iş analistlerinin, özellikle proje yöneticisinin yer almadığı projelerde üzerinde çalışması gereken paydaş analizi süreci olmalıdır. 
Paydaş analizinden yararlanılan alanlardan biri de paydaşlarla ilişkilerin sürdürülmesi yani paydaş yönetimidir. Bugün iş dünyasındaki herkes insanların veya grupların farklı ilgileri ve etkileriyle karşılaşırlar. Özellikle daha büyük kurumlar sadece sahiplerin ihtiyaçlarıyla değil, pek çok değişik gruplar için örneğin çalışanlar, kamu ilgi grupları mesela çevresel organizasyonlar, stratejik ortaklar, gazeteciler, kamu denetleyicileri v.s., bu liste her firma için değişebilir özelliktedir. Bundan dolayı, bütün işler kompleks bir ilgi ve etki sistemi içinde yönetilir. Yönetim bu dişsal güçleri kurumsal amaçlarla birlikte kabul etmek yerine onları değerlendirmelidir (Donaldson ve Preston, 1995; akt. Bat1, 2006, s.11).

Bu bireyler ve gruplar kendi amaçlarını gerçekleştirmek için organizasyona bağlı olan ve organizasyonlar da amaçlarını gerçekleştirilmek için bireylere ve gruplara bağlı olan gruplardır, bunlar paydaşlar olarak adlandırılırlar. Paydaş yönetiminin önemi günlük işlere bağlı değildir. Buna karşıllk her şeyden ünce uzun dönemli stratejik düşünce ile ilgilidir.

Paydaş yönetimi; anahtar paydaşların tanımlandığı ve bu paydaşların desteklerinin sağlandığı bir süreçtir. Paydaş analizi paydaş yönetiminin ilk adımıdır, en önemli paydaşlar tanımlanır ve bu paydaşlar anlaşılmaya başlanır. İkinci adım, paydaşlar güçlerine ve ilgilerine göre önceliklendirilir ve güç ilgi tablosuna yerleştirilir. Son adım da paydaşları nelerin motive ettiğinin ve paydaşların nasıl kazanılacağının anlaşılmasıdır. Paydaş analizi tanımlandıktan sonra ikinci adım paydaş planlamasıdır. Bu süreç paydaşların nasıl yönetileceğinin ve paydaşların desteğinin nasıl sağlanacağının planlanmasıdır.

Paydaş planlaması için bir planlama sayfası oluşturulmalı ve plan hazırlanırken şu adımlar izlenmelidir.

1. Plan sayfası güç ilgi tablosundan faydalanılarak güncellenir.

2. Yaklaşım paydaş yönetimine göre düşünülür ve gözden geçirilir.

3. Her bir paydaştan ne beklendiği ve istendiği üzerine çalışılır.

4. İfade edilmek istenen mesajlar tanımlanır.

5. Faaliyetler ve iletişimler tanımlanır.

İyi bir paydaş yönetimi büyük projelerde sık sık ortaya çıkan politikaların yönetilmesinde yardımcıdır. Böylece yöneticilerin destek sağlamasina yardımcı olur (Batı, 2006.s.11-12).

Paydaş Yönetimi, başarılı insanların başkalarının desteğini kazanmada kullandıkları önemli bir disiplindir. Bu yönetim, onlara kendi projelerinin 
başarılı, başkalarının projelerinin ise başarısız olduğunu garanti eder. Paydaş Analizi ise, kendi tarafınıza kazanabileceğiniz anahtar (temel) insanları belirlemede kullanılan bir tekniktir. Daha sonra, bu insanları tarafınıza kazanmak için paydaş planlamasını kullanırsınız( Jacques, 2001).

Paydaş analizi aynı zamanda bir araştırma yöntemidir. Nitel araştırma yaklaşımının yöntemlerinin biri olarak paydaş analizi araştırmacıların ve akademisyenlerin kullanımına açıktır. Bu konu eski kuşak tarafından çok bilinmediğinden araştırmacılıkta pozitivist paradigma tutkusu araştırmacıları kısıtlamaktadır.

Paydaş analizi, örgütsel psikolojiye göre; herhangi bir fenomenin çevresinde çok sayıda olan fenomenin kendisini etkileyen, kendisinden etkilenen ve bir şekilde etkisi olan etkenlerin, ilgili tarafların, grupların varlığ görüşüne dayanan bir araştırma yaklaşımıdır (Altunışık, 2004).

Bir nitel araştırma sırasında paydaş analizinin tercih edilmesinin bazı sonuçları vardır. Bu sonuçlardan birisi Vatan(2015)'ın Altunışık ve arkadaşlarından, aktardığına göre; "Paydaş analizinde pratik olarak ilgili partilerin belli miktar tanımlayıcı verilere ulaşması söz konusudur. Bazı durumlarda, eğer nicel veriler ispatlanabilir ve yararlı ise; bunların da analize tabi tutulması mümkündür. Bu bağlamda paydaş analizi sadece nitel bir çerçevede düşünülmemelidir" şeklinde ifade edilmektedir(Vatan, 2015, s.130).

Burgoyne(1994) 'e göre; paydaş analizi bazı nitel varsayımlarla örtüşmektedir:

1. Gerçekliğin subjektif doğası gereği farklı gruplar aynı fenomenifarklı görebilir ve ifade edebilirler.

2. Durumlar tek bir amaç ya da planın yansıması olmak zorunda değildir. Ancak, çoklu amaç ve planların etkileşiminden doğabilirler.

3. Bir davranışın ortaya çıkışının post-yapısalcı yaklaşımdaki yansıması olarak aktörler insan doğasının basit bir yapısı şeklinde sabit bir donamımdan ziyade kültürel değerleri içselleştiren birer kültürel yazılım olarak düşünülürler.

Bu yaklaşımın özü; araştırmaya konu olan fenomenle ilgisi olan partilerin belirlenmesi ve bunların hareketleri, kanı ve davranışları hakkında veri toplanması ve analiz edilmesi şeklinde özetlenebilir. Paydaş analizi- 
nin başlı başına bir araştırma ve istatistik yöntemi; diğer nitel ve nicel araştırma yöntemlerine yardımcı bir yöntem olmak üzereiki önemli fonksiyonu bulunmaktadır.

\section{Paydaş Temelli Yaklaşımın Yararları}

Projenizin ilk dönemlerinde, en etkili paydaşların projeyi biçimlendirmek için söyledikleri fikirlerden faydalanılabilir. Bu sadece onların projeyi destekleme ihtimalini arttırmakla kalmaz, aynı zamanda onların fikirleri projenin kalitesini de arttırır. Etkili paydaşların desteğini kazanmak, daha çok kaynağa sahip olmaya yardımcı olur. Bu da projenin başarılı olma ihtimalini arttırır.

Paydaşlarla başından itibaren ve sık sık iletişim kurarak, onların projenizde ne yapıldığını tamamen anlamalarını ve projenin yararlarını kavramalarını sağlayabilir. $\mathrm{Bu}$ da demektir ki; gerektiğinde projenizi aktif bir şekilde destekleyebilirler. İnsanların projeye karşı tepkilerinin ne olabileceğini öngörebilir ve planda insanların desteğini kazanacak şekilde faaliyetler oluşturulur(Jacques, 2001).

\section{Paydaş Analizi Yöntemleri}

Paydaş analizi konusunda yapılan literatür taramasında genelde 3 yöntemin öne çıtığ görülmektedir. Bu yöntemlerin en önemlisi sosyal ağ analizi yöntemidir. Bunun yanında bazı çalışmalarda güç/çıkar matrisi ile paydaş çevrimi yöntemi de kullanılmaktadır.

\section{Sosyal A $\breve{g}$ Analizi}

Sosyal A $\breve{g}$ Analizi; paydaşların niteliklerine odaklanan paydaş çevrimi metodolojisi ve güç/ çıkar matrislerinin aksine, bir ağdaki paydaşlar arasındaki ilişkilere odaklanmaktadır. Örneğin bir inşaat projesi karmaşık yapıda çok unsurlarla etkileşimli bir proje sistemidir (Bourne ve Walker, 2006; Pryke, 2006; akt. Uygun, 2018, s.101). Dolayısıyla, inşaat projesinin paydaşlar arasındaki ilişkilerinin karmaşık ve dinamik olması muhtemeldir. Bunun gibi karmaşık ve dinamik ilişkilerin yoğun olduğu projeler ve 
/ veya sektör analizlerinde sosyal ă̆ analizi kullanımı yaygınlaşmıştır (Uygun, 2018,s.101).

Sosyal ağ analizi (Social Network Analysis-SNA), belirli bir alanda araştırma konuları, yazarlar ve kurumlar arası ilişkilerin incelenmesi ile bilgi bağlantılarının tanımlanması ve yorumlanmasında kullanışlı bir yaklaşım olarak gösterilmektedir (Scott, 2000). Bir sosyal ağ; temelde kişilerin veya diğer çoklukların (kurum vb.) aralarındaki etkileşimi, yardımlaşmayı ve etkileri gösteren bir yapı olarak tanımlanmaktadır. Bu bağlamda sosyal ağ analizi, sosyal yapıyı aktörlerden (düğümlerden) ve aktör çiftlerini birbirine bağlayan ilişki kümelerinden oluşan bir ağ olarak görerek, sosyal yapıyı ve etkilerini incelemektedir (Gürsakal, 2009, s. 184).

Geleneksel araştırma sadece proje yöneticileri ve paydaşlar arasındaki ilişkiyi analiz etmekte, paydaşlar arasındaki etkileşimi göz ardı etmektedir(Pryke, 2006; akt. Uygun, 2018 ,s. 102). Sosyal A $\breve{g}$ Analizi, proje ortamını çeşitli ilişkilerle bağlantılı bir sistem olarak yorumlamakta, paydaşlar arasındaki karşılıklı ilişkiyi ve ilgili kişilerin sosyal davranışlarını haritalamak için kullanılmaktadır (Uygun, 2018, s. 102).

\section{Güç/ Çıkar Matrisi}

Paydaşlar analiz edilirken paydaşların pozisyonları, çıkarları, aralarındaki ilişkiler, etkileri, sahip oldukları ağlar ve diğer özellikleri hakkında, ayrıca geçmişteki, şu andaki pozisyonları ve gelecekteki potansiyellerine atfen sorular sorulmaktadır (Brugha \& Varvasovszky, 2000, s. 239). Bu sorulara verilecek cevaplar, paydaşların etki ve çıar düzeylerini belirlemede kullanılabilmektedir. Karar alma süreçlerinde uygulamaya koymak için ilgili aktörlerin davranışları, niyetleri, aralarındaki etkileşimleri, gündemleri, çıkarları, etkileri veya sahip oldukları kaynaklar hakkında enformasyon edinmek söz konusudur (Brugha \& Varvasovszky, 2000, s. 241; akt. Uygun, 2018, s. 103).

Johnson ve Scholes (1999), paydaşların beklentilerini ve gücünü belirleyerek paydaş stratejileri geliştirmek amaciyla bir model ortaya koydular. Güç / Çıkar Matrisi adını verdikleri model, paydaşları sınıflandırarak işletmenin her bir paydaş grubuyla oluşturması gereken ilişki türünü gös- 
termeye çalı̧̧maktadır. Bu bağlamda paydaşlar işletme üzerindeki çıkarlarına ve bu çıkarları elde etme gücüne sahip olma düzeylerine bağlı olarak sinıflandırılmaktadır ( akt. Sarıkaya, 2011, s.55).

Güç-çıkar matrisi analizi, aynı zamanda işletmelerin iletişim yönetimi açısından da risk analizinin önemli bir etabıdır. Bu bağlamda hem risklerin tespit edilmesi, hem de yeni iş olanaklarının belirlemesi sağlanmış olur (Global Corporate Governance Forum, 2009; akt. Uygun, 2018, s. 103). İşletmeler, bu matrislerden elde edilen sonuç bulguları karar verme aşamasında strateji geliştirmek için kullanmaktadırlar. Böylelikle paydaşların işletmelerin hangi kararlarını reddeceği ya da destekleyeceği belirlenebilmektedir. Güç/ Çıkar matrisi daha çok örgüt içi paydaş analizi çalışmalarında tercih edilmektedir. Daha dinamik ve karmaşık yapıdaki örgütler arası sektör paydaş analizi çalışmalarında aşağıda anlatılan olan yöntemler geliştirilmiştir(Uygun, 2018, s. 103).

\section{Paydaş Çevrimi}

Proje yönetiminde, proje bazlı işlerde paydaş analizi ve paydaş ilişkilerini araştırmada kullanılan yöntemlerden biri paydaş çevrimi yöntemidir (Bourne, 2006; akt. Uygun, 2018,s.104). Birçok proje yönetimi yöntemi, proje paydaşlarını belirlemekte ve ardından tüm iletişim stratejilerini tanımlamaktadır. Paydaşlar projenin vizyonunu veya hedeflerini desteklemediği için başarısız olmaktadır.

Paydaş yönetimi oldukça zor bir süreçtir. Proje yöneticisi ve proje ekibi üyeleri, projeyi pek çok yönden etkileyebilecek çeşitli gruplar ve kişiler (kendileri de dahil olmak üzere) ile ilişkilerini belirlemeli, bunlara dahil olmalı ve sürdürmelidir. Paydaş Çevrimi yöntemi, proje yöneticisini ve proje ekibini projenin ilişkilerini yönetmede desteklemek üzerine geliştirilmiş bir araçtır. Bu bağlamda paydaşların beklenti ve ihtiyaçları bilinerek, tanınmakta olup, ilişkilerin yönetimine dâhil edilmesini sağlamaktadır (Bourne, Walker 2006; akt. Uygun, 2018, s.104). 


\section{Paydaş Analizi Yönteminin Proje Hazırlamada Kullanılması}

Paydaş Analizi'ndeki ilk adım, paydaşların kim olacağını belirlemektir. Sonraki adım, bu insanların gücüne, etkisine ve ilgisine (çıkarına) karar vermektir ki böylelikle hangisine odaklanılması gerektiği bilinir. Son adım ise, projeye nasıl bir tepki gösterebileceklerini bilmek ve böylelikle de onların desteğini kazanabilmek için, en önemli paydaşları iyi tanımalı, bu analiz paydaş haritasına konulmalıdır. Bu aracı kullandıktan ve bir paydaş haritası oluşturduktan sonra, her bir paydaşla nasıl iletişim kuracağının planlanması için paydaş planlama aracı kullanılabilir(Jacques, 2001).

Thompson(2007) 'a göre; paydaşların katılımı; bilgiye dayalı kararlar almaya, projenin daha ilk aşamalarında paydaşlar arasında görüş birliğinin oluşturulmasına ve farklı paydaşların projeyi izleyebilmesi bakımından şeffaflık sağlamaya yarar.

Paydaş analizi sonuçları proje tasarlarken; sorunları analiz ederken, hedefleri belirlerken ve stratejiyi seçerken kullanılır. Paydaş analizi sonuçlarının proje yazımında ne şekilde kullanıldığı aşağıda özetlenmiştir.

\section{Proje Özeti veya Ön Teklifi}

Ortakların, hedef grupların ve nihai faydalanıcıların belirlenmesi; paydaş analizinin özeti, liste veya tablo (anahtar paydaşlar ve ilgileri) projeye dahil edilecek aktörler ve bu aktörlerarası ilişkilerin aktarılmasını yansıtır.

\section{Proje Dokümanı}

Thompson, (2007) a göre bir proje dökümanı aşağıdaki bölümlerden oluşur.

- Gerekçelendirme: Hedef grubun seçilme nedenleri, bu grubun ihtiyaçlarının ve sorunlarının tanımlanması. Proje ile ihtiyaçlara nasıl cevap verilecek?

- Proje Yöntemi: Çeşitli aktörlerin projedeki rollerinin ve projeye katılımlarının tanımlanması ve bu rollerin onlara veriliş nedenini ortaya koyar. 
- Beklenen Sonuçlar: Hedef gruplar/faydalanıcılar üzerine etkisi; genel durum, teknik ve yönetim kapasitesidir.

- Mantıksal Çerçeve: Projenin uygulanmasında bilim ve teknolojiden nasıl yararlanılacağının ifade edilmesi gerekir.

- Faaliyetler: Proje kapsamında yapılacak etkinlikler bir takvime bağlı olarak ifade edilmelidir.

- Riskler ve varsayımlar: Projenin başarısını etkileyecek olumsuzluklar ve başarılı olmasını sağlayacak fırsatlar iyi tesbit edilmelidir.

\section{Paydaş Analizi Yönteminin Adımları}

Paydaş Analizinin ilk adımı, paydaşların kim olacağıyla ilgili beyin fırtınası yapmaktır. Sonraki adım, onlara gücüne ve ilgisine (çıkarına) göre öncelik vermek ve bunu güç/Illgi levhasına yerleştirmektir. Son adım ise, paydaşları neyin motive edeceğine ve onların nasıl desteğini kazanacağına karar vermektir(Jacques, 2001).

\section{Birinci Adım: Paydaşların Belirlenmesi}

Yukarıda değinildiği gibi, paydaş analizinizdeki ilk adım, paydaşlarının kim olacağıyla ilgili beyin fırtınası yapmaktır. Bunun bir parçası olarak, çalışmadan etkilenen, çalışma üzerinde etkisi veya gücü olan ya da çalışmanın başarılı olup olmamasıyla ilgilenen bütün insanlar düşünülür(Thompson, 2007).

Aşağıdaki tablo, işde ya da projelerde paydaş olabilecek insanların bazılarını göstermektedir: Patron, hissedarlar, hükümet, üst düzey yöneticiler, anlaşılan partnerler, ticaret birlikleri, iş arkadaşları, tedarikçiler, basın, toplum, ekip, sermayedarlar, çıkar grupları, müşteriler, analistler, kamu, potansiyel müşteriler, gelecekte işe dahil olacak kişiler, aile üyeleri paydaşları oluşturmaktadır. 
Tablo 1. Olası Paydaşlar(Jacques, 2001).

\begin{tabular}{lll}
\hline Patron & Hissedarlar & Hükümet \\
\hline Üst düzey yöneticiler & Anlaşılan partnerler & Ticaret birlikleri \\
\hline İş arkadaşları & Tedarikçiler & Basın \\
\hline Ekip & Sermayedarlar & Çıkar grupları \\
\hline Müşteriler & Analistler & Kamu \\
\hline Potansiyel müşteriler & Gelecekte işe dahil olacak kişiler & Toplum \\
\hline Aile & & \\
\hline
\end{tabular}

Paydaşlar hem kurumlar hem insanlar olabilmesine rağmen, sonunda insanlarla iletişim kurmak zorunda olunduğu unutulmamalıdır. Bir paydaş kurumda doğru paydaşların belirlendiğinden emin olunmal1$\operatorname{dir}(J a c q u e s, 2001)$.

\section{Paydaşlar ve Ortaklar}

Paydaşlar; projeden doğrudan veya dolaylı, olumlu veya olumsuz etkilenen ve/veya projeyi etkileyen bireyler, kurumlar veya gruplardır. (örneğin; hükümet kurumları, STK'lar, özel sektör, belediyeler, aileler). Ortaklar ise projeyi birlikte uygulayan taraflardır.

\section{Yararlanicılar}

a) Hedef Kitle: Proje faaliyetlerinden doğrudan ve olumlu etkilenecek kişi ve kurumlar (örn. eğitim katılımcıları).

b) Nihai Yararlanıcı: Uzun vadede ve dolaylı olarak toplumsal ya da sektörel ölçekte olumlu etkilenecekler (örn. Çocuklar).

c) Proje Ortakları: Projeyi uygulayan taraflar (hedef kitle grubundan da olabilir).

\section{Örnek Paydaş Gruplan}

Yerel halk, kullanıcılar, tüketiciler, STKlar, kamu kurumları (örn; bakanlıklar, valilikler, belediyeler),çıkar grupları (örneğin; birlikler, meslek odaları), özel sektör, uluslararası kurumlar (örneğin; donör kuruluşlar). 
Clarkson (1995, s.106-107) paydaşları; birincil ve ikincil paydaş olarak sinıflandırmıştır. Yazara göre; hissedarlar ve yatırımcılar, çalışanlar, müşteriler ve tedarikçiler, hükümetler ve topluluklar birincil paydaş grubunu oluşturmaktadır. Bu grubun ortaklığı veya katılımı sağlanmazsa, şirketin hayatta kalması mümkün olamaz. Şirket ve birincil paydaş grupları arasında yüksek düzeyde bir karşılıklı bağımlılık vardır. İkincil paydaş grupları ise; şirketi etkileyen ya da şirket faaliyetlerinden etkilenen ancak, şirketle ilgili işlemlerde bulunmayan ya da şirketin hayatta kalması için çok da önem taşımayan gruplar olarak tanımlanmaktadır. Bu tanım çerçevesinde medya ve özel ilgi grupları ikincil paydaşlar olarak kabul edilmektedir.

Mitchell ve diğerleri (1997) paydaşları önem derecesine göre; farklı gruplara analiz edilmesine yardımcı olacak bir paydaş analiz modeli geliştirmişlerdir. Bu modelde paydaşlar güç, meşruluk ve aciliyet gibi üç temel değişken dikkate alınarak analiz edilirken, paydaşlar yedi gruba ayrilmaktadır.

Yazarlara göre paydaşlar; güç, meşruluk ve aciliyet durumlarına göre sinıflandırılmaktadır. Yedi grupta tanımlanan paydaşların farklı zamanlarda farklı yönetimsel beklentileri olmaktadır. Uyuyan (1), ihtiyari (2) ve talep eden (3) paydaş grupları düşük seviyede ilgi gösteren grupları oluşturmaktadır. Oysa baskın (4), tehlikeli (5) ve bağımlı (6) paydaşlar beklentisi olan gruplardır. Nihai (7) paydaşlar ise belirtilen üç değişkene ilişkin özelliklere sahip olduklarından şirket yöneticileri bu grubun ilgi alanlarını ya da beklentilerini acil bir şekilde ele almalı ve tatmin edilmeleri için yoğun çaba harcamalıdırlar (Mitchell ve diğ., 1997, s. 878). Aksi taktirde nihai paydaşlar şirketin bu durumdan büyük zarar görmesine neden olacaktır(akt. Hoştut, 2018, s.191).

\section{Paydaşların Belirlenmesinde Cevap Aranan Sorular}
a) Sorundan kimler olumsuz etkileniyor?
b) Kimler çıkar sağlıyor?
c) Projeye destek verenler ve karşı çıkanlar kimlerdir?
d) Savunmasız ve hassas gruplar saptand $1 \mathrm{~m} 1$ ?
e) Kimler direk hangileri dolaylı olarak etkileniyor?
f) Tüm paydaşların özellikleri nasıldır? 
İkinci Adım: Paydaşların İlgilerinin ve Çıkarlarının Tespit Edilmesi (Paydaşlara Öncelik Verilmesi)

- Paydaşların her birinin projeden beklentileri nelerdir?

- Paydaşların projeden sağlayabilecekleri muhtemel yararlar nelerdir?

- Hangi paydaşların çıkarları, projenin hedefleri ile çelişmektedir?

- Paydaşların her biri projeye ne gibi mali katkı sağlayabilecek durumdalar? Bunu sağlamaya istekliler mi? (Thompson, 2007).

Çalışmadan etkilenen kurumların ve insanların yazılı olduğu uzun bir listeye sahip olunabilir. Bunlardan bazıları çalışmayı engelleyebilecek ya da ilerletebilecek güce sahip olabilir. Bazıları ne yapıldığı ile ilgili olabilir, baz1ları umursamayabilir(Jacques, 2001).

Şekil 2' de gösterilen boş şablon üzerindeki güç/İlgi levhasına paydaşlar yerleştirilir. Onlar iş üzerinde gücü olan ve iş üzerinde ilgisi olanlara göre siniflandirılır.

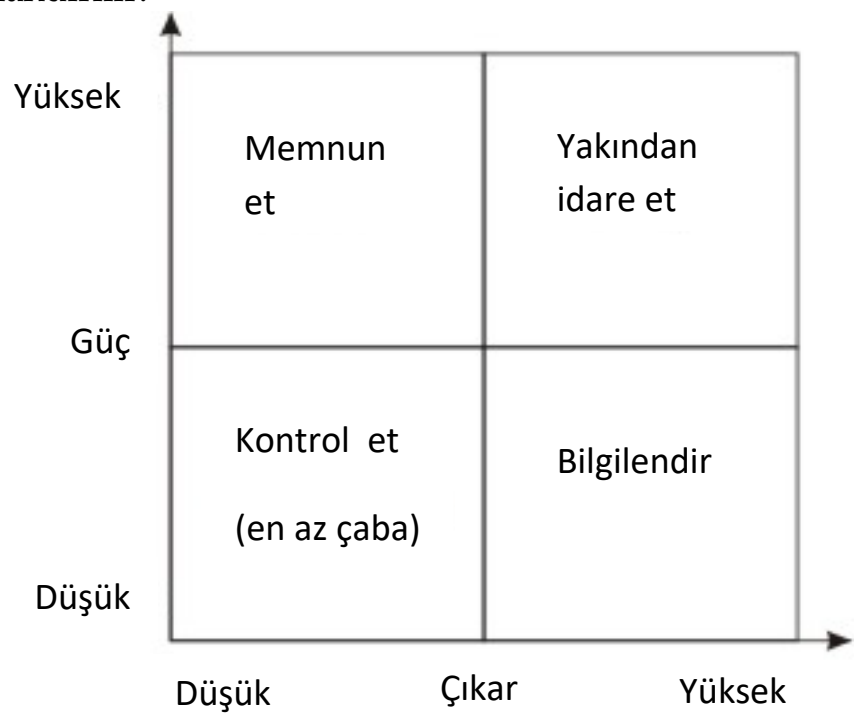

Şekil 2. Paydaş Önceliği için Güç/Çıkar Levhası, (Jacques, 2001) 
Örneğin, patron projeler üzerinde muhtemelen yüksek güce, etkiye ve çıkara sahiptir. Aile proje üzerinde yüksek çıkara sahip olabilir fakat muhtemelen yüksek güce sahip değildir. Şeklin üzerindeki birinin pozisyonu onunla yapması gereken faaliyetleri gösterir:

- Yüksek Güç, İlgili İnsanlar: Bunlar tamamen adanılması ve onları memnun etmek için büyük çaba sarfedilmesi gereken kişilerdir.

- Yüksek Güç, Az İlgili İnsanlar: Bu insanları memnun etmek için yeterli çalışma yapılmalıdır; fakat, mesajdan sıkılacakları kadar çok olmamak şartıyla.

- Düşük Güç, İlgili İnsanlar: Bu insanlar yeteri kadar bilgilendirilmeli ve onlarla konuşarak başlıca (büyük) sorun olmadığı belirtilmelidir. Bu insanlar projenin detayları konusunda genellikle çok yardımsever olabilirler.

- Düşük Güç, Az İlgili İnsanlar: Tekrar, bu insanlar kontrol edilmeli, fakat, aşırı iletişimle rahatsız edilmemelidir(Jacques, 2001).

\section{Üçüncü Adım: Paydaşların Güçlerinin ve Etkilerinin Saptanması(Temel Paydaşlarnn Anlaşılması)}

Şu anda kilit paydaşlar hakkında daha fazla bilgiye ihtiyaç vardır. Proje hakkında muhtemelen nasıl hissedecekleri ve nasıl tepki gösterecekleri bilinmelidir. Ayrıca, onların projeye en iyi şekilde nasıl dahil edileceği ve onlarla en iyi nasıl iletişim kurulacağı bilinmelidir. Paydaşların anlaşılmasina yardımcı olabilecek temel sorular:

- İşin (projenin) sonucuyla ilgili hangi ekonomik ya da duygusal çıkara sahipler?

- Bu çıkar olumlu mu yoksa olumsuz mu?

- Paydaşlarınız çoğunu ne motive eder?

- Hangi bilgiyi istiyorlar?

- Bilgiyi nasil almak istiyorlar?

- Mesajı onlara aktarmanın en iyi yolu nedir?

- İşle ilgili güncel fikirleri nedir? Bu fikirleri iyi bilgiye mi dayanmaktadır?

- Onların fikirlerini genellikle kim etkiler ve onların sizinle ilgili fikirlerini kim etkiler? 
- Onların kendi doğrularına göre, bu etkileyen kişilerin bazıları bu yüzden mi önemli paydaşlardır?

- Eğer onlar projeye karşı muhtemelen olumlu değilse, projeyi desteklemek onlara ne kazandıracak?

- Eğer onları kazanabileceği düşünülmüyorsa, onların muhalefetini nasıl idare edeceksiniz?

- Onların fikirlerinden, başka kim etkilenebilir?

- Bu kişiler kendi doğrularına göre sizin paydaşlarınız olur mu?

Bu sorulara cevap vermenin en iyi yolu paydaşlarınızla direkt olarak konuşmaktır. İnsanlar görüşleri hakkında genelde oldukça açıktırlar ve insanlarla iyi bir ilişki kurmada ilk adım onların fikirlerini sormaktır.

Buraya kadar öğrenilenler paydaş haritasının üzerinde özetlenebilir. Böylelikle hangi paydaşların projeyi engelleyici veya eleştirici ve hangilerinin yandaş ve destekleyicisi olmasının beklendiği kolaylıkla görülebilir. Bunu yapmanın iyi yolu; yandaşları ve destekleyicileri yeşil renkle, engelleyici ve eleştiricileri kırmızı renkle ve diğer tarafsız olanları turuncu renkle göstererek renklere göre kodlama yapmaktır.

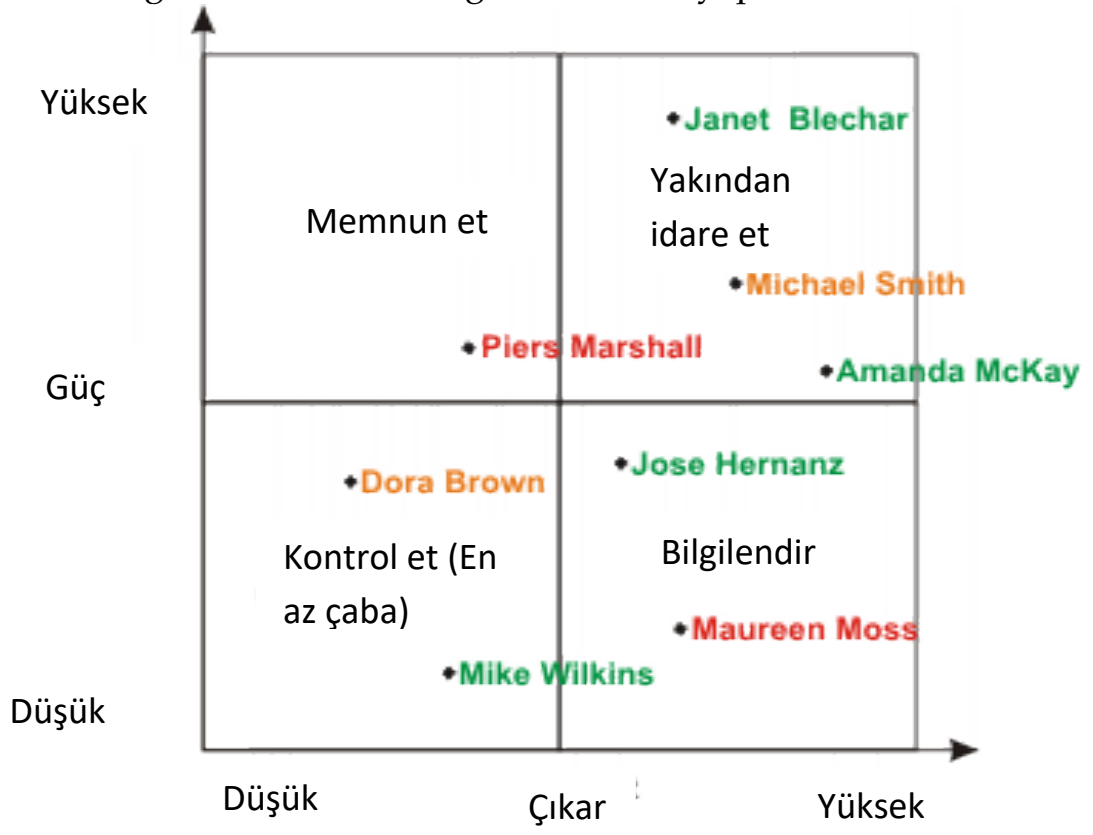

Şekil 3. Paydaşlarnn İşaretlendiğ̀i Güç/Çıkar Levhası Örneği 
Şekil 3, bunun bir örneğini göstermektedir. Bu örnekte, Piers ve Michael'ı projenin yararları konusunda ikna etmek için çok fazla çaba gösterilmesi gerektiği görülebilir. Janet ve Amanda'da güçlü destekleyiciler olarak iyi idare edilmelidir.

\section{Örnek}

İşteki (şu anki görev, yapmak istenilen bir iş ya da yeni bir proje) kendi paydaş analizi örneği oluşturulabilir.Tam bir paydaş analizi örneği oluşturulur. Paydaşlarla olması gerektiği kadar etkili iletişim kurulup kurulmadığını sorulur. Destekleyicilerin daha fazla desteğini almak ve eleştiricileri kazanmak için hangi faaliyetleri yapılabilir?

\section{Temel (Anahtar) Noktalar}

Yapılan iş ve yürütülen projeler daha önemli oldukça, daha fazla insanı etkiler. Bu insanlardan bazıları mevki ve projeleri düşürecek güce sahiptir. Diğerleri, işin güçlü destekleyicileri olabilir.

Paydaş yönetimi, temel (kilit) paydaşların belirlendiği ve onların desteğinin kazanıldığı bir süreçtir. Paydaş analizi, paydaşların belirlenip, en önemli paydaşların anlaşılmaya başlandığı, paydaş yönetimi'nin ilk adımidir(Jacques, 2001).

Muhtelif paydaşların birbirleri arasındaki ilişkiler nelerdir?, Kimin kimin üstünde gücü vardır?, Kim kime bağımlıdır?, Hangi paydaşlar örgütlenmiştir?, Bu örgütlenme nasıl etkilenebilir veya bu örgütlenmenin üzerine nasıl inşa edilebilir?, Kaynakları kim kontrol etmektedir?, Bilgi kimin kontrolündedir?, Yasal sorumluluk kimdedir?(Thompson, 2007).

Dördüncü Adım: Paydaş Katılımı Stratejisinin Oluşturulması (Paydaşlarn Neyin Motive Edeceğine Ve Onların Desteğinin Nasıl Kazanılacağına Karar Verme)

Paydaşların, ilgileri, çıkarları, etkileri ve güçleri dikkate alınarak, hangi düzeyde ne zaman sürece katılmaları gerektiği belirlenmeli, gerektiği takdirde projeye nasıl katkı sunabilecekleri ayrıntılarıyla ifade edilmeli$\operatorname{dir}($ Thompson, 2007; Jacques, 2001 ). 
Paydaş analizi sürecinin, projeden etkilenecek ve işi doğrudan kullanacak gruplar ile gereksinim analizi sürecinin çalışılabilmesi için oldukça önemli olduğunu görüyoruz. Paydaş analizi sürecinin atlanmaması ve doğru yapılmasının, analiz sürecinin eksiksiz ve zamanında tamamlanmasındaki ön koşul olduğu unutulmamalıdır.

\section{Sonuç ve Öneriler}

Bu çalışma özellikle proje hazırlayan öğrencilere ve araştırmacılara rehberlik yapma hedefine yönelik hazırlanmıştır. Araştırma ve uygulama projesi hazırlayanların paydaş analizi yapma konusunda bir eğitimden geçirilmeleri sağlanabilirse; projenin sonuca götürecek şekilde uygulanması mümkün olacaktır. Bu konuya yeterince önem verilmediğinde kaynak israfı ortaya çıkmaktadır. Gelişmekte olan bir ülke için kaynak israfının telafisi olanaksızdır.

Stratejik yönetim anlayışının gereği olarak hazırlanan stratejik planlarda gördüğümüz olumsuzlukların birçoğu paydaş analizinin ciddi yapılmamasından kaynaklanmaktadır. Bu planı hazırlayanlar paydaşları tanımlama ve analiz etmede yetersizlik göstermektedirler. Bunun telafi edilmesi için sorumlu elemanların bu konuda bilinçlendirilmeleri gerekmektedir. Bu çalışmanın stratejik plan hazırlayanlara yol gösterici olmasını bekliyoruz.

Yeni yatırımların ve yeni iş analizlerinin yapıldığı zamanlarda yatırımcıların, ortakların ve finansal destek sunanların sistemli çalışmaları gerekmektedir. Yatırım ve iş analizi yaparken öncelikle paydaşların iyi analiz edilmesi yanlış adımlar atılmasını önleyecektir. Kalkınma hamlesi içerisinde olan bir ülke olarak her türlü israfı önlememiz gerektiği fikri genel kabul gördüğüne göre bu alanda da paydaş analizinin önemini kavratmak durumundayız. Bu çalışmayla ilgili personele rehberlik yapılması hedeflenmiştir.

Paydaşların iyi analiz edilmesi sürecin yönetilmesi sırasında da etkili olmaktadır. Paydaş yönetimi diye adlandırdığımız bu süreç projenin başarılı olmasında, yatırımın verimli olmasında ve stratejik planın uygulanmasında sonuçları tayin etmektedir. Bu açıdan kurum yöneticilerinin paydaş yönetimi konusunda bilinçli hareket etmeleri için bilgilendirilmeleri önem taşımaktadır. Bu makale biraz da bu amaca yönelik hazırlanmıştır. 
Bu çalışmayla paydaş analizinin aynı zamanda bir nitel araştırma yöntemi olduğunun anlatılması amaçlanmıştır. Nitel araştırmacılıkta bu yöntem araştırmaya konu olan fenomenle ilgisi olan etkenlerin zamanında belirlenmesi ve bunların hareketleri, kanı ve davranışları hakkında veri toplanması ve analiz edilmesi şeklinde tanımlanabilir. Bu çalışmayla paydaş analizinin başlı başına bir araştırma ve istatistik yöntemi; diğer nitel ve nicel araştırma yöntemlerine yardımcı bir yöntem olmak üzere iki önemli fonksiyonu bulunduğu gerçeğinin kabul görmesi amaçlanmaktadır.

Bu sonuçlardan hareketle paydaş analizi konusunda toplumun bilgilendirilmesinin, konunun çok boyutlu olarak tartışılmasının projelerin, stratejik planların ve yatırım planlarının geniş toplum kesimlerince anlaşılmasının sağlanması için paydaş analizi konusunda daha fazla yayın yapılması, medyanın dikkatinin çekilmesi önemli görünmektedir. Bu konuda sonuç alabilmek için: kapsamlı yayınların yapılmasını, okullarda sosyal içerikli derslerde konuya yer verilmesini, araştırma yöntemleri dersinde ve araştırmacıların eğitiminde bu yöntemin üzerinde durulmasını öneriyoruz. 


\title{
EXTENDED ABSTRACT
}

\section{Stakeholder Analysis}

\author{
* \\ M. Zeki İlgar - Semra Coşgun İlgar \\ Biruni University - Ministry of National Education
}

\begin{abstract}
As a qualitative research and statistical method, stakeholder analysis is used while producing solution to a problem or preparing a project; the method is used for determining problem/project relations, analyzing power and effect, researching accession strategies of all of the stakeholders that may be affected from the possible project and for evaluating project results.

In other words, stakeholder analysis is a method of determining relations of stakeholders with the problem/project, their power in the process or impact on it, and their strategies of accession; the stakeholders in question are affected either from the subject of a research or from a possible project.
\end{abstract}

\section{Definition and Importance of Stakeholder Analysis}

The notion of stakeholder that we use today was firstly defined by F. Edward Freeman as (1984, p.25): “Any group or individual who can affect or is affected by the achievement of the organization's objectives". Defining the stakeholders, gathering data about them, analyzing these data and transforming them into significant information for the organization are expected to positively contribute to future decisions in a company (Brugha and Varvasovszky, 2000, p.239).

Stakeholder management is a discipline (doctrine) that successful people use to win support from others. This management guarantees the success of its users' projects while on the other hand guarantees the failure of others'. Stakeholder analysis, on the other hand, is a technique used for determining the key (the basic) figures that you can win over. After completing this process, you use Stakeholder planning in order to win these individuals round (Jacques, 2001). 
According to Burgoyne (1994), stakeholder analysis complies with some qualitative assumptions:

1. As reality is intrinsically subjective, different groups can see and express the same phenomenon differently.

2. Circumstances don't have to be the reflections of one single goal or plan. But they can arise from the interaction of multiple purposes and plans.

3. Actors, as the reflection of the occurrence of a behavior in poststructuralist approach, are imagined as cultural software who with inherent cultural values rather than steady hardware in the shape of a simple structure of human nature.

The essence of this approach can be summarized as determining parties that have relations with the phenomenon which is the subject of the research, collecting and analyzing data about their positions and movements.

Stakeholder analysis has two important functions:

1. It is a research and statistics method all by itself,

2. It is an assistant method for other qualitative and quantitative research methods.

\section{Steps of Stakeholder Analysis Method}

The first step of stakeholder analysis is to make brainstorming about the possible stakeholders. The next step is to prioritize these possible allies according to their power and interest (profit) and to place this information into the Power/Interest grid. The last step is to decide what motivates stakeholders and how to win their support (Jacques, 2001).

\section{$1^{\text {st }}$ Step: Defining Stakeholders (Define your Stakeholders)}

The first step in your stakeholder analysis is to identify your stakeholders, to make brainstorming about them. In order to be able to do this, think about all of the individuals who are affected from your work, who have impact or power on your work, who are interested in the success or failure of your work (Thompson, 2007). 
$2^{\text {nd }}$ Step: Determining Stakeholders' Interests and Benefits (Prioritize Your Stakeholders)

- What are the expectations of each stakeholder from the project?

- what are the possible benefits that stakeholders can present?

- The benefits of which stakeholders are in conflict with the goals of the project?

- What kind of financial contribution can be presented for the project by each stakeholder? Are they willing to do this? (Thompson, 2007).

Right now, you may have a list with the names of institutions and individuals who are affected from your work. Some of these might have the power to block or develop your work. Some of them might be interested in what you do, some others may not be interested (Jacques, 2001).

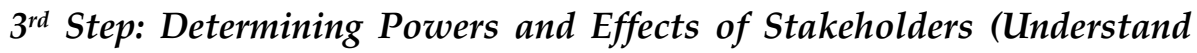
your Basic (Key) Stakeholders)

Right now, you need more information about your key stakeholders. You should know how they might feel about your project and how they will react. On the other hand, you should know how to involve them into your project and how to communicate with them.

$4^{\text {th }}$ Step: Creation of Stakeholder Participation Strategy (Decide on what motivates the stakeholders and how you will win their support)

The timing and level of stakeholder participation should be determined by analyzing their interest, effect and power. The contributions that they may give when necessary should be stated in details (Thompson, 2007; Jacques, 2001 ).

\section{Kaynakça / References}

Altunışık, R.,Coşkun, R.,Bayraktaroğlu, S. ve Yıldırım, E. (2004).Sosyal bilimlerde araştırma yöntemleri. Sakarya: Sakarya Kitabevi. 30.03.2019 tarihinde http://arvedaarastirma.com/paydas-analizi/ adresinden erişilmiştir. 
Batı, G.B. (2006).Paydaş teorisi ve bankalarda paydaş analizi. Yayınlanmamış Yüksek Lisans Tezi. Uludağ Üniversitesi, Sosyal Bilimler Enstitüsü, Bursa.

Burgoyne, J. G. (1994).Stakeholder analysis, In (C. Cassell And G. Symon Eds), Qualitative Methods In Organizational Research: A Practical Guide, (p.187-207), London:Sage.

Ekin, D.(2016) Paydaş Analizi. [Blog yazısı] 12.03.2019 tarihinde http://www.demetekin.com.tr/paydas-analizi// adresinden erişilmiştir.

Gürsakal, N. (2009). Sosyal ă̆ analizi Pajek, Ucinet ve Gmine uygulamalı. Bursa: Dora Yayınları.

Hoştut, S.(2018). Türk üniversitelerinin paydaş analizi. Erciyes İletişim Dergisi Akademia, 5(3), 187-200.

Jacques C. (2001). Stakeholder analysis and natural resource management, stakeholder in formation system, Carleton University, Ottawa, June .

Reed, M. S. (2008). Stakeholder participation for environmental management: a literatüre review. Biological conservation, 141(10).

Sarıkaya, M. (2011) Paydaş yaklaşımı bağlamında işletme-paydaş etkileşimi ve stratejik paydaş analizi. Ankara:Ankara Sanayi Odası Yayın Organi.

Scott, J. P. (2000). Social network analysis A handbook. (2. bs.). London:Sage Publications.

Sönmez, S. ve Uğurluoğlu, Ö. (2017). Sağlık kurumlarında paydaş analizi. Uluslararası Yönetim İktisat ve İşletme Dergisi, 13(1).

Thompson, R. (2007). Stakeholde analysis. 2011 https://www.mindtools.com/pages/article/new PPM_07.htm adresinden erişilmiştir.

Uygun, M. (2018).Türkiye'de să̆lık turizmi alanında paydaş analizi: Ankara'da sosyal ă̆ analizi yaklaşımı uygulaması. Yayınlanmamış Doktora tezi, Ankara Yıldırım Beyazıt Üniversitesi Sosyal Bilimler Enstitüsü, Ankara.

Vatan, A.(2015). Destinasyon pazarlaması kapsamında Bilecik ili turizminin değerlendirilmesine yönelik paydaş analizi. Yayınlanmamış Doktora Tezi, Sakarya Üniversitesi, Sosyal Bilimler Enstitüsü, Sakarya.

\section{Kaynakça Bilgisi / Citation Information}

İlgar, M. Z. ve İlgar-Coşgun, S. (2019). Paydaş analizi. OPUS-Uluslararası Toplum Araştırmaları Dergisi, 14(20), 1835-1860. DOI: 10.26466/ opus.574116 